\title{
Evaluating a train-the-trainer educational intervention to raise standards of care, within the nursing home sector in the United Kingdom
}

\author{
Andrew Clifton ${ }^{1}$, Kay De Vries ${ }^{1}$, Karan Juttla ${ }^{1}$, Nikki Welyczko ${ }^{1}$, Rachael Carroll ${ }^{1}$ and Gabriella O'Keeffe ${ }^{2}$ \\ ${ }^{1}$ Leicester School of Nursing and Midwifery, Faculty of Health and Life Sciences, De Montfort University, Leicester, UK \\ ${ }^{2}$ Head of Quality Transformation, Quality Directorate, NHS Corby \& NHS Nene Clinical Commissioning Groups, UK
}

\begin{abstract}
Objective: As a response to service needs and project development by the East Midlands Health Innovation Education Cluster, now the Health Education East Midlands, an education programme intervention was developed to raise the standards of clinical and non-clinical care, particularly within the nursing home sector. This paper discusses the development of the intervention based on the "train-the-trainer" model presenting data which highlights improved service quality and a reduction in NHS costs as a result of the training.

Methods: The programme measured pre and post impact of the programme on the knowledge and confidence of the staff who took part and captured the impact of the overall training in terms of reported measures such as falls, urinary tract infections, referrals from nursing homes to an emergency department, and number of GP call outs to nursing homes.

Results: Analysis revealed; an increase in knowledge and confidence of staff following training, an improvement in outcomes for all key measures including; falls, urinary tract infections, referrals to emergency departments, and number of GP callouts. The data also highlights cost reduction in all these areas based on cost estimates.

Conclusions: There is evidence that the delivery of an education intervention in nursing homes, based on local/regional needs and adopting a 'train-the-trainer' approach can improve outcomes for residents and reduce costs for providers, including the NHS, in regard to reduced GP callouts and hospital admissions. It is important to have pre and post data collection measures in place to capture its impact on service quality and evaluate the cost effectiveness of programmes.
\end{abstract}

\section{Introduction and background}

In the United Kingdom (UK) education initiatives in the care home sector have been a relatively new development and have only been a focus in this environment since the 1980s. Aylward, et al. [1] undertook one of the first literature reviews of education and training activities in the care home sector. The reviewers' highlighted one of the main problems for the sector within the UK is the high turnover of staff; this remains a significant problem. The high levels of vacancy rates and staff turnover in the UK care home sector indicates that employers are struggling to find, recruit and retain suitable people to the sector [2] and there is potential for workforce shortage in the future [3]. Due to high employee turnover, low staffing levels and poor skill mix, investment in staff training is challenging despite Care Quality Commission (CQC) regulations [4] that require delivery of training. Consequent to the above issues and challenges the quality of care in meeting the basic needs of residents is compromised $[5,6]$. In this paper we consider education interventions in nursing homes; outline the development of the education intervention with a particular focus on the "train-the-trainer" model that was fundamental to the overall approach to the project, including a discussion on how the learning sessions were organised and delivered. Methods for data collection and analysis are presented followed by a presentation of the results of this evaluation.

\section{Education interventions in care homes}

There are multiple methods used to deliver education interventions within the care home sector. Some reviews of these have addressed the general use of education approaches in long-term care [1]. Many educational interventions are augmented with clinical interventions (see examples in the rapid review by the Centre for Policy on Ageing) [7]. Also, most reviews have focused on a specific area of care need, including for example: end-of-life care [8] dementia (see for example $[9,10])$; prescribing [11]; and medication use [12]. Anstey, et al. [8] found most educational interventions were very brief and there were no reports of e-learning, blended learning or reflective practice in their review of end-of-life care education.

There are a number of challenges involved in the education and training of staff working in the care home sector. Ousey, et al. [13]

${ }^{\star}$ Correspondence to: Andrew Clifton, Leicester School of Nursing and Midwifery, Faculty of Health and Life Sciences, De Montfort University, Leicester, UK, E-mail: andrew.clifton@dmu.ac.uk

Key words: education, training, train-the-trainer, nursing homes, care homes, costeffectiveness

Received: November 28, 2018; Accepted: December 13, 2018; Published: December 17, 2018 
suggest that Registered Nurses (RNs) working in care homes have often received little or no training since their pre-registration nursing programme. This creates educational challenges related to support, supervision, continued professional development (CPD) revalidation [14] and retention [15].

There are significant practical difficulties in releasing large numbers of care home staff for training at any one time, resulting in repetition of training sessions on multiple occasions. In addition, the costs of sending staff on external courses can be a prohibitory factor for many establishments, meaning that only essential mandatory training is covered. As such, it is essential that training and training methods for the care home sector are sustainable to enable education to be more widely disseminated amongst care teams. Thus, establishing a rolling programme of education is imperative to ensure that all staff working in the home have the opportunity to receive training and education [16].

However, the delivery of educational programmes alone is not a sufficient condition for success [17] and there is minimal evidence that knowledge gained from training programmes is sustained in the long term, in this environment. Most studies do not consider organisational and system factors when planning and implementing training initiatives. This may account for difficulties encountered in the sustained transfer of knowledge to practice [1].

\section{Train-the-trainer interventions}

The term "train-the-trainer" is not well defined in the literature possibly due to its self-explanatory title. This has not impeded its use in the health sector [18-20]. It is often a model used to "scale up" the numbers of people able to carry out a new skill or practice $[21,22]$. In essence, a train-the-trainer approach is where the training of a group of people is undertaken by an expert in the specific field. The group attendees are then expected to return to their area of work and replicate the training with others. This may be their peers [23] or patients [24] or academics with students [22].

The advantages of this style of training are multiple. For instance, the train-the-trainer model has the ability to reach a wider audience through the subsequent training (trainer led training) than traditional training methods where all are trained by the expert (expert led training) [20,21]. When those that have received the primary training return to their area to reproduce the learning, there has been found to be supplementary benefits; locality-based trainers were viewed as more accessible than expert trainers for those looking for further support [23]. It was also found that, those delivering the successive training often have the advantage of a connection with the local community and an awareness of the contextual factors that can inhibit use and roll-out of the new practice. Addressing contextual issues during training can positively effect sustainability $[20,21]$. Also, it is a less costly and more convenient way of training due to reduced travel costs, reduced time away from work and less payment for expert trainers [21].

This model has been found to be as effective as a traditional training programme $[21,22]$ and there was a similar level of learner impact found when comparing expert-led training with trainer-led training [23]. When these findings are coupled with the benefit of trainers being based in less accessible communities, this becomes an appealing model for scaling up the amount of people implementing new skills [23].

The role of the training providers was to deliver 'train-the-trainer' sessions to selected staff from the homes so that they could cascade the training and modify it as necessary to meet the requirements of their care environment. The requirement to tailor training to the requirements of the individual home has been highlighted in a number of studies [25-27]. The need to work collaboratively with nursing home staff to address their individual needs rather than imposing a 'one size fits all' has been identified by Lansdell and Mahoney [27].

The expert led train-the-trainer sessions were delivered as a oneday course, with a view to subsequent cascade sessions delivered in the trainers' nursing homes being shorter and more targeted to the requirements of their specific nursing home environment and client groups. Sessions were a combination of both theory and practical clinical skills and were delivered in an informal, flexible and interactive way to engage staff in learning. It was essential that cascade trainers were not only knowledgeable about the areas covered but also had the confidence to be able to educate their peers.

\section{The Education Intervention}

In keeping with the trainer-lead model of train-the-trainer, a number of nursing home staff became trained to become cascade trainers who could deliver training and education to colleagues (Registered Nurses and Care Assistants) in their respective nursing homes, making this a more sustainable and cost-effective approach to training. The training providers were all Registered Health Care Professionals and employed as academic staff at Leicester School of Nursing and Midwifery, De Montfort University. Staff delivering the trainer sessions were considered to be 'experts' in the particular subject areas.

As a response to service needs and project development by the East Midlands Health Innovation Education Cluster (EMHIEC), now the Health Education East Midlands (HEEM), the education programme was developed. The overall aims of the programme were to improve service quality and help manage NHS costs. However, it also had several other targets. The programme had the potential to reduce avoidable admissions, develop high quality care for frail and older people, and ensure there was a safe and sustainable workforce to meet the healthcare needs of the East Midlands population. In addition to clinical skills, the programme offered training in urinary catheter management, falls management, and delirium/dementia assessment factors which are major contributors to avoidable admissions.

Within one year, the project team disseminated the programme. Twenty-eight nursing homes and 20 registered nurses were trained in its use. All training delivered as part of this programme was delivered via the "train-the-trainer" approach, whereby each nursing home nominated a lead to undertake the training and then help cascade the training within their own organisations.

\section{Delivery of education intervention}

Learning sessions were organised with the help of the NHS Corby \& NHS Nene Clinical Commissioning Groups (CCG). The aim was to educate nursing home staff with the necessary skills to enable either prevention, or the early intervention and treatment, of conditions that are often associated with an older population. The education delivery aimed to:

Improve confidence of staff in dealing with a variety of common nursing home care requirements and increase staff skills in the following areas:

- venepuncture

- syringe driver care

- diabetes management 
- catheterisation/continence

- nutritional assessment and support

- pressure ulcer assessment and management

- anaphylaxis

- effective communication/referral

- management of delirium

- how to safely and effectively reduce use of antipsychotic medication

- Create a safer Care Home environment that is fit for purpose

\section{Methods}

The programme aimed to measure the impact on knowledge and confidence of the staff that took part. A questionnaire was administered prior to implementation of a training package, followed by a repeat after the training package. On a Likert scale from 1 (strongly disagree) to 5 (strongly agree). Participants reported their knowledge and confidence relating to falls, catheter management, delirium assessment and care home skills. With the help of the Quality Improvement team, NHS Nene and NHS Corby CCG, the programme team was able to collect some useful measures using data sheets designed specifically for this programme. Data collection was particularly challenging, and involved the Quality Improvement Team to ensure data sheets were returned at baseline and post intervention. The programme team identified a number of measures for which data needed to be collected. Specifically, it was important to obtain data on the number of falls (of which the number of falls that were referred to hospitals), the number of clients in nursing homes with catheters inserted, the number of urinary tract infections diagnosed, the number of referrals to the emergency department and the number of GP callouts. The data for these measures was collated for six months prior to training and six months post training. The data was based on self-reported figures by the nursing homes who were asked to provide this information using the data collection sheet designed for the programme. Basic descriptive statistics were used to present the outcome data.

\section{Results}

\section{Knowledge and confidence}

The questionnaire analysis of the falls training delivery indicated that there was an increase in knowledge and confidence of staff following training. Staff felt that they were more confident in working with older people and managing falls. A central objective of the falls training was to ensure that nursing home staff were aware of the potential impact that a fall can have on an older person.

Catheter management training did not have a significant impact on increase in knowledge and confidence of staff. The education delivered for care home skills had a positive impact on the knowledge and confidence of staff. Attendees of the training felt more confident that they had knowledge to care for patients with Type 2 Diabetes. Staff also felt that they had the knowledge and skills required when taking bloods and that they felt more confident when dealing with sub-cutaneous fluids.

\section{Impact of training in terms of reported measures}

Of the 28 nursing homes that provided training, only nine were able to provide this data for the evaluation. The training delivery to those nine nursing homes resulted in improvement in outcomes for all key measures; such as falls, urinary tract infections, referrals to emergency departments, and number of GP callouts (Figure 1).

With regard to falls, the number of falls that were referred to hospital declined by $50 \%$ post training. The project team was confident that this improvement in outcome measures could be directly attributable to the training delivered to these nine nursing homes that have provided this data, primarily since these nursing homes did not receive any other training during this period.

\section{Cost reduction and savings}

There was some cost reduction associated with the project. These costs were estimates, and further robust data collection methods are required to ensure a more accurate calculation. Table 1 below summarises the costs of the some of the measures that were reported by the nine nursing homes:

Based on the above estimates, there has been some cost reduction in terms of Falls, Urinary Tract Infections, Referrals to Emergency departments and Number of GP callouts. The cost avoided under these categories is summarised below (Table 2).

As can be seen from Table 2 below, there is a good potential for avoiding unnecessary costs through training in nursing homes. This data reflects costs avoided by only nine nursing homes. Hence, in further similar education interventions a more robust data collection measure should be established to ensure all nursing homes in receipt of training submit their reported measures, there is a potential for even higher cost saving in the area.

Table 1. Cost of events: Sources: NHS Nene and NHS Corby CCG, NHS Institute

\begin{tabular}{|l|l|}
\hline Event & Cost per unit \\
\hline Falls referred to Hospitals & $£ 5,345$ per patient \\
\hline Urinary Tract Infection Diagnosed & $£ 2,000$ per UTI \\
\hline Referrals to Emergency Departments & $£ 1,600$ per referral \\
\hline Number of GP callouts & $£ 100$ per visit \\
\hline
\end{tabular}

Table 2. Potential costs avoided

\begin{tabular}{|l|c|c|c|c|}
\hline Event & $\begin{array}{c}\text { Total Pre- } \\
\text { Training }\end{array}$ & $\begin{array}{c}\text { Total Post } \\
\text { Training }\end{array}$ & Difference & $\begin{array}{c}\text { Potential } \\
\text { Costs Avoided }\end{array}$ \\
\hline $\begin{array}{l}\text { Falls referred to } \\
\text { Hospitals }\end{array}$ & 16 & 8 & $50 \%$ & $£ 42,760$ \\
\hline $\begin{array}{l}\text { Urinary Tract } \\
\text { Infection Diagnosed }\end{array}$ & 108 & 70 & $35.20 \%$ & $£ 76,000$ \\
\hline $\begin{array}{l}\text { Referrals to } \\
\text { Emergency } \\
\text { Departments }\end{array}$ & 48 & 25 & $47.90 \%$ & $£ 36,800$ \\
\hline Number of GP callouts & 309 & 272 & $12.00 \%$ & $£ 3,700$ \\
\hline
\end{tabular}

\section{Data Measures}

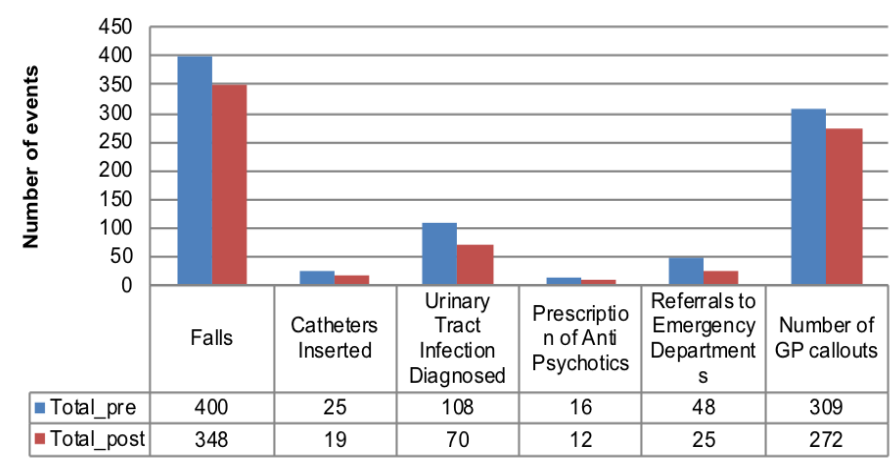

Figure 1. Outcomes for key measures 


\section{Limitations}

Data was collected from nine of 28 nursing homes that were in receipt of the educational intervention, thus affecting the reliability of this evaluation. It may also be argued that the small sample size is biased, suggesting that only those who had positive outcome measures completed the data entry sheets. Though a larger sample would increase the reliability of the data, the data captured is a valid representation of the impact of this type of training approach for participating nursing homes. In relation to cost-savings, these were only estimates or projections, as a robust health economic evaluation was not undertaken. However, there is evidence of potential higher cost savings in some areas within other health care services.

\section{Discussion}

This article has demonstrated how an educational intervention improved service quality and helped manage NHS costs for frail and older people based on information gained from nine Nursing Homes in Northamptonshire. The evaluation highlights the positive impact of developing a needs-based educational intervention. The education programme was developed based on data gathered to understand local/ regional challenges. Once the content was agreed, a 'train-the-trainer' approach was adopted. This project supports extant evidence that this approach is both effective in terms of spreading knowledge and applying it to practice and is cost effective. There is no clear guidance for implementing a train-the-trainer model in health education [28].

However, learning is significantly influenced by the context and setting in which it occurs [29]. Once trained, staff members were able to re-produce their learning specific to their workplace settings and address the challenges of cultural organisations that are quite often not considered in the development of education programmes. The transfer of learning into practice is most effective when delivered by those knowledgeable in the traditions, histories and cultures of their organisation. A 'train-the-trainer' model allows for a more holistic approach to training to be developed, that takes into consideration the conditions and constraints of the workers. For training to be effectively rolled out, staff not only need to be knowledgeable within the specific fields but also need to feel confident to deliver the training. It is important therefore that the programme focuses on developing such skill sets encouraging staff to be both confident and flexible in their approach to training.

Although the transfer of knowledge into practice is an area widely discussed in the literature, little evidence is provided for ways of measuring/capturing this process. Although this project captured information regarding confidence and knowledge impact of the programme on staff, it also gathered data to capture the impact this training had on service quality. Data entry sheets were given to all 28 nursing homes to report measures pre and post training regarding the number of; falls, urinary tract infections, referrals to emergency departments, and number of GP callouts. Only nine of the 28 nursing homes successfully captured this information. The remaining 19 reported non-completion due to issues concerned with time constraints and high staff turnover. Whilst it is important to have these measures in place, it is equally important to ensure that such care facilities have the resources in place to collect such data. Considering the high demands on the health care sector as highlighted in the literature [1], future programmes should consider funding a researcher to capture the information or, encourage such data collection to be a part of routine practice. Indeed, further robust data collection methods would support a more accurate calculation of cost savings. Using current cost estimates, this evaluation has also demonstrated that cost reduction was a result of the educational intervention.

\section{Conclusion}

There is currently very limited data in the literature that discusses the various ways of capturing information to demonstrate cost savings. This evaluation thus highlights the importance of capturing pre and post data on reported measures to show its impact on service quality and evaluate the cost effectiveness of the programme. Such data will support and encourage the investment of similar education programmes across the country to help meet the current challenges faced by other health care services when supporting frail and older people.

\section{References}

1. Aylward S, Stolee P, Keat N, Johncox V (2003) Effectiveness of Continuing Education in Long-Term Care: A Literature Review. The Gerontologist 43: 259-271.

2. Skills for Care (2017) The state of the adult social care sector and workforce in England, 2017. Skills for Care, Leeds.

3. Franklin B (2015) The end of formal adult social care: A provocation by the ILC-UK ILC-UK, London.

4. Care Quality Commission (CQC) (2017) Shaping the future CQC's strategy for 2016 to 2021. Care Quality Commission, Newcastle upon Tyne.

5. Royal College of Nursing (2012) Persistent challenges to providing quality care: An RCN report on the views and experiences of frontline nursing staff in care homes in England. Royal College of Nursing, London.

6. Hussein S, Ismail M, Manthorpe J (2016) Changes in turnover and vacancy rates of care workers in England from 2008 to 2010: panel analysis of national workforce data. Health Soc Care Community 24: 547-556.

7. Centre for Policy on Ageing (2014) The effectiveness of training and other interventions in care homes.

8. Anstey S, Powell T, Coles B, Hale R, Gould D (2016) Education and training to enhance end-of-life care for nursing home staff: a systematic literature review. $B M J$ Supportive \& Palliative Care 0: 1-9.

9. Raymond M, Warner A, Davies N, Baishnab E, Manthorpe K, et al. (2014) Evaluating educational initiatives to improve palliative care for people with dementia: A narrative review. Dementia 13: 366-381. [Crossref]

10. Fossey J, Masson S, Stafford J, Lawrence V, Corbett A, et al. (2014) The disconnect between evidence and practice: a systematic review of person-centred interventions and training manuals for care home staff working with people with dementia. Int J Geriatr Psych 29: 797-807.

11. Loganathan M, Singh S, Franklin BD, Bottle A, Majeed A (2011) Interventions to optimise prescribing in care homes: Systematic review. Age Ageing 40: 150-162.

12. Nishtala P, Mclachlan A, Bell S, Chen T (2008) Psychotropic prescribing in long term care facilities: impact of medication reviews and educational interventions. Am J Geriat Psychiat 16: 621-632. [Crossref]

13. Ousey K, Kaye V, McCormick K, Stephenson J (2016) Investigating staff knowledge of safeguarding and pressure ulcers in care homes $J$ Wound Care 25: 5-11.

14. Nursing \& Midwifery Council (NMC) (2015) Revalidation London: NMC

15. Spilsbury K, Hanratty B, McCaughan D (2015) Supporting nursing in care homes London: RCN Foundation.

16. Shepherd M, Jones J, Frost J, McLeod K (2008) Targeted diabetes education for care home teams Diabetes and Primary Care 10: 261-269.

17. Nolan M, Davies S, Brown J, Wilkinson A, Warnes T, et al. (2008) The role of education and training in achieving change in care homes: a literature review. Journal of Research in Nursing 13: 411-433.

18. Levine SA, Brett B, Robinson BE, Stratos GA, Lascher SM, et al. (2007) Practicing physician education in geriatrics: lesson learned from a train-the-trainer model. Journal of American Geriatrics Society 55: 1281-1286.

19. Stratos GA, Bergen MR, Hallenbeck J (2006) Faculty development in end-of-life care evaluation of a national train-the-trainer program. Acad Med 81: 1000-1007. 
Clifton A (2018) Evaluating a train-the-trainer educational intervention to raise standards of care, within the nursing home sector in the United Kingdom

20. Tobias CR, Downs A, Eddens S, Ruiz J (2011) Building blocks for peer success: lessons learned from the train the trainer program. AIDS Patient Care STDS 26: 53-59. [Crossref]

21. Yarber L, Brownson CA, Jacob RR, Baker EA, Jones E, et al. (2015) Evaluating a train-the-trainer approach for improving capacity for evidence-based decision making in public health. BMC Health Serv Res 15: 547-557. [Crossref]

22. Greif R, Black Becker C, Hilderbrandt $T$ (2015) Reducing eating disorder risk factors: a pilot effectiveness trial of a train-the-trainer approach to dissemination and implementation. International Journal of Eating Disorders 48: 1122-1131

23. Zisblatt L, Hayes SM, Lazure P, Hardesty I, White JL, et al. (2017) Safe and competent opioid prescribing education; increasing dissemination with a train the trainer program. Subst Abus 38: 168-176.

24. Shen Z, Jiang C, Chen L (2018) Evaluation of a train-the -trainer program for stable coronary artery disease management in community settings: a pilot study. Patient Education and Counselling 101: 256-265.
25. Heeley-Creed D, Brown K, Hill J (2007) Carlisle and District diabetes training in nursing and residential care homes Practical Diabetes International 24: 15-18.

26. Mitchell E, Lawes H (2007) Improving education in falls prevention Nursing \& Residential Care 9: 407-409.

27. Lansdell J, Mahoney M (2011) Developing competencies for end-of-life care in care homes International Journal of Palliative Nursing 17: 143-148.

28. Orfaly RA, Frances JC, Campbell P, Whittemore B, Joly B, et al. (2005) Train-thetrainer as an Educational Model in Public Health Preparedness. J Public Health Man 11: 123-127.

29. Billett S (2001) Learning in the Workplace: Strategies for Effective Practice. Allen \&Unwin: Australia.

Copyright: $(02018$ Clifton A. This is an open-access article distributed under the terms of the Creative Commons Attribution License, which permits unrestricted use, distribution, and reproduction in any medium, provided the original author and source are credited. 